Journal of Engineering Sciences, Assiut University, Vol. 38, No. 1, pp. 177-193, January 2010

\title{
DESIGN AND CONSTRUCTION OF A WIND TUNNEL FOR ENVIRONMENTAL FLOW STUDIES
}

\author{
Hamoud A. Al-Nehari", Ali K. Abdel-Rahman ${ }^{\star *}$, Abd El-Moneim \\ Nassib $^{* *}$ and Hamdy M. Shafey \\ Department of Mechanical Engineering, Faculty of Engineering, Assiut \\ University, Assiut 71516, EGYPT \\ * Graduate Student, **Associate Professor, *** Professor \\ E-mail: $\underline{h \text { nahary@hotmail.com }}$
}

(Received December 26, 2009 Accepted January 28, 2010)

\begin{abstract}
This paper presents the design, construction, and preliminary characterization of the atmospheric boundary layer wind tunnel facility for environmental flow studies at Assiut University. The wind tunnel is a low speed-open loop and driven by a $2 \mathrm{~kW}, 4 \mathrm{~m}^{3} / \mathrm{s}$, axial flow fan. The main core of the designed wind tunnel is the long section (3.5 $\mathrm{m}$ length) devoted to produce and simulate the atmospheric boundary layer $(A B L)$ for various environmental flow studies. The simulation of the ABL can be achieved for different earth surface conditions by inserting of well designed spires arrangement and arrays of roughness elements. The design procedure and the construction steps for the main components of the wind tunnel are summarized. The experimental results of the mean axial velocity profiles for different fan speeds are presented and discussed for the preliminary characterization of the wind tunnel. The results show that the present wind tunnel is capable to maintain long run steady flow characteristics and reproducible flow patterns. The use of designed triangular spires and cube roughness elements is successful in simulating real ABL of thickness up to $600 \mathrm{~m}$ corresponding to urban area.
\end{abstract}

KEYWORDS: Atmospheric boundary layer, Low speed-open loop wind tunnel, Wind tunnel characterization, Environmental flow.

\section{INTRODUCTION}

Experimental and theoretical techniques are being extensively used in environmental flow studies. Measurements in environmental flow studies can be done at full scale, and/or at laboratory scales in wind tunnels. The wind tunnels have been used for long time as useful tool for investigating various flow phenomena and research of industrial aerodynamics [1]. Environmental studies using wind tunnels are described as physical modeling of the atmospheric boundary layer (ABL) [2] to gain better understanding of complex field phenomena, especially the dispersion of pollutants in urban atmospheres. Advantages of the wind tunnel technique include: (1) well controlled flow circumstances, (2) adjustment of variables at will, and economy, (3) easy reproduction of the experimental conditions, and (4) accurate data generation for validating the Computational Fluid Dynamics (CFD) simulations and field measurements. 


\section{NOMENCLATURE}

\section{Alphabetic Symbols}

$A R \quad$ Entrance height-to-width ratio of contraction cone

$A_{s} \quad$ Total area of spires, $\mathrm{m}^{2}$

$b \quad$ Width of the spire, $\mathrm{m}$

$C_{D 0} \quad$ True drag coefficient

$C_{f} \quad$ Local skin friction coefficient

$C R$ Contraction cone ratio

$H \quad$ Height of the boundary layer development section, $\mathrm{m}$

$h \quad$ Height of the spire, $m$

$H_{i} \quad$ Half inlet height of the contraction cone, $\mathrm{m}$

$H_{o} \quad$ Half outlet height of the contraction cone, $\mathrm{m}$

$H_{r} \quad$ Height of the cubical roughness element, $\mathrm{m}$

$L \quad$ Length of the curved part of the contraction cone, $\mathrm{m}$

$N \quad$ The number of spires

$\operatorname{Re} \quad$ Reynolds number, $\left(\operatorname{Re}=u_{\delta} . x / v\right)$ $s \quad$ The pitch between two spires, ( $s$ $=h / 2), \mathrm{m}$

$T$ Temperature, $\mathrm{K}$

$u \quad$ Mean axial velocity, $\mathrm{m} / \mathrm{s}$

$u_{\delta} \quad$ Mean axial velocity at height $\delta$, $\mathrm{m} / \mathrm{s}$

$W \quad$ Width of the boundary layer development section, $m$

$x \quad$ Along-wind coordinate distance, $\mathrm{m}$

$x_{f} \quad$ Distance downstream of the spires at the end of the boundary layer development section, $m$

$y \quad$ Cross-wind (lateral) coordinate distance, $m$

$z \quad$ Vertical coordinate distance, $\mathrm{m}$

\section{Greek Symbols}

$\alpha \quad$ The power law exponent

$\delta^{*} \quad$ The boundary layer thickness, $\mathrm{m}$

$\theta \quad$ Blockage factor

$\lambda_{f} \quad$ Frontal area density of roughness element

Wind tunnels are generally classified into four groups according to flow speed. They are; subsonic or low-speed, transonic, supersonic, and hypersonic. Subsonic or low-speed wind tunnels are the most common type used in many applications. Atmospheric boundary layer wind tunnels (ABLWTs) are usually of the subsonic or low-speed type. Transonic wind tunnels are common in the aircraft industry since most commercial aircraft operate in this regime. Supersonic wind tunnels can be used to investigate the behavior of jet engines and military aircrafts. Hypersonic wind tunnels find their applications in rockets and space vehicles. A further way to categorize low speed wind tunnels is by dividing them into open loop or closed loop wind tunnels [3]. The open loop wind tunnels are usually working on suction type flow induced by axial flow fan.

The basic physical requirements of an ABLWT are a front flow straightening section producing uniform cross sectional flow, a long working section to develop a boundary layer flow characteristics through appropriate floor roughness elements [4]. The roughness elements act as earth surface roughness (soil conditions, slopes, plants, topography...etc) to artificially simulate the earth's atmospheric boundary layer. Additional devices such as spires, vortex generators, trips and barriers [5-10] are commonly used to accelerate the rate of growth and to produce a fully developed boundary layer. Also, cooling and heating facilities are used to produce a thermally stratified boundary layer $[10,11]$. Several design criteria are commonly taken into consideration in wind tunnels design and construction have been listed for some existing wind tunnels in $[3,4]$. 
Due to the increase of researches and consulting projects involving environmental flow studies in Assiut University, Egypt, there was a necessity to build an ABLWT that can be used in conducting such researches and projects. The aim of this paper is to present the design, construction, and preliminary characterization of an ABLWT facility in the Laboratory of Environmental Studies and Research at the Mechanical Engineering Department of Assiut University. The present ABLWT, which is of a low-speed (up to $4 \mathrm{~m} / \mathrm{s}$ ), open-loop type, is designed with the common criteria required for proper simulation and investigation of environmental conditions. The current design has the advantages of using spires, roughness elements, and heating unit. An after heater settling section is designed to counter balance the heaters effects and to get again a uniform smooth flow. The wind tunnel test section is designed to easy handling of fabricated models simulating different urban areas objects and buildings (as well as other earth surface conditions), such simulation facilities investigating the effects of air pollutants and their dispersion in urban and other atmospheres. Some experimental and numerical results of the flow velocity distributions are presented for the assessment of the preliminary characterization of the present wind tunnel.

\section{DESIGN CONSIDERATIONS AND MAIN FEATURES}

The structure of an ABL is complex and cannot be physically modeled exactly in a wind tunnel. However, one can obtain a good stimulation of a natural ABL by considering a few important requirements representing the fundamental similarity criteria [4]. These requirements are; (1) similarity of relative surface roughness, (2) kinematics simulation of airflow, (3) boundary layer velocity distribution and turbulence, (4) matching of Reynolds number, Rossby number and Richardson number, and (5) matching the zero pressure gradients found in the full-scale area. Such similarity criteria have been considered in the design procedure and selection of the various components and operating conditions of the present wind tunnel. Moreover, some criteria are considered to achieve a design that is cost-effective, having uniform flow with no separation inside the inlet, and suitable for performing the required tests and experiments. These design criteria are: open circuit, thermally stratified, good flow quality, contraction ratio, $\mathrm{CR}$, in the range of $4-9[11,12]$, air flow velocity in the test section up to $4 \mathrm{~m} / \mathrm{s}$, low noise level, ease of maintenance and accessible test section. Finally, flow separation must be avoided in the boundary layer development section to minimize losses and to keep stable flow. The design features and main components of the present ABLWT are shown in Fig. 1. The main flow sections of the ABLWT (Fig. 1-a) are:

- flow straightening section (I), to produce uniform axial flow,

- long flow development section (3.9 m) (II), to develop the desired boundary layer flow characteristics,

- test section (III), and

- flow support section (IV), to generate the required axial flow inside the wind tunnel using a variable speed fan.

The present wind tunnel construction consists of the following eight components (see Fig. 1-b for details) listed in order from front to back: (1) an upstream 
settling section, (2) a contraction cone, (3) an air-flow heating unit, (4) an after heaters settling section, (5) a boundary layer development section, (6) a test section, (7) a transition and flexible connection, and (8) an axial flow fan. These components have been designed and fabricated in the workshop of Faculty of Engineering, Assiut University. Figure 2 shows a photographic view of the wind tunnel construction assembly of the fabricated components with measuring and control facilities in the Laboratory of Environmental Studies and Research at the Mechanical Engineering Department.

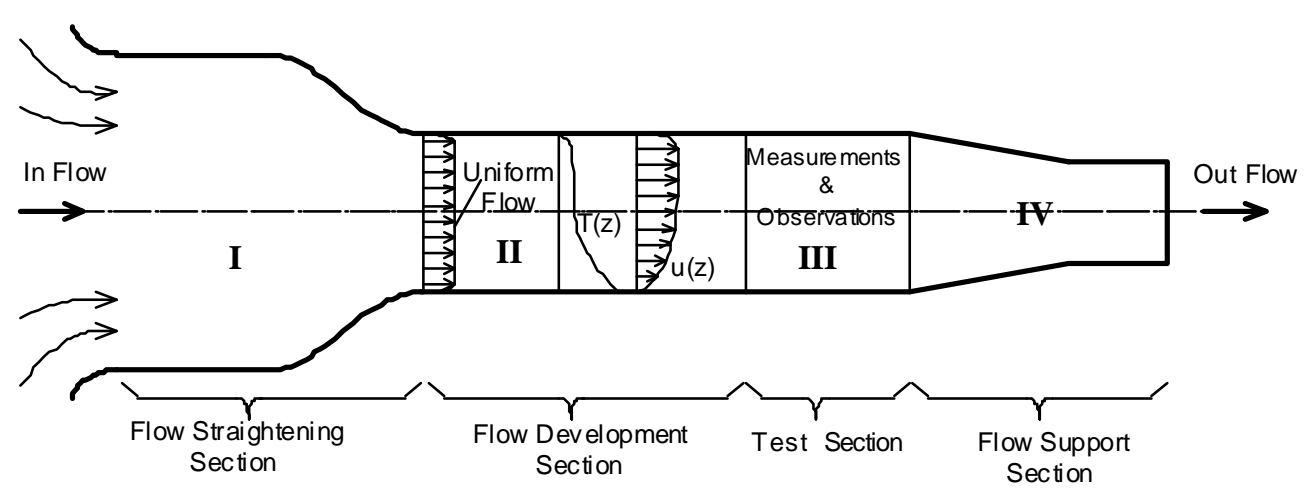

(a)

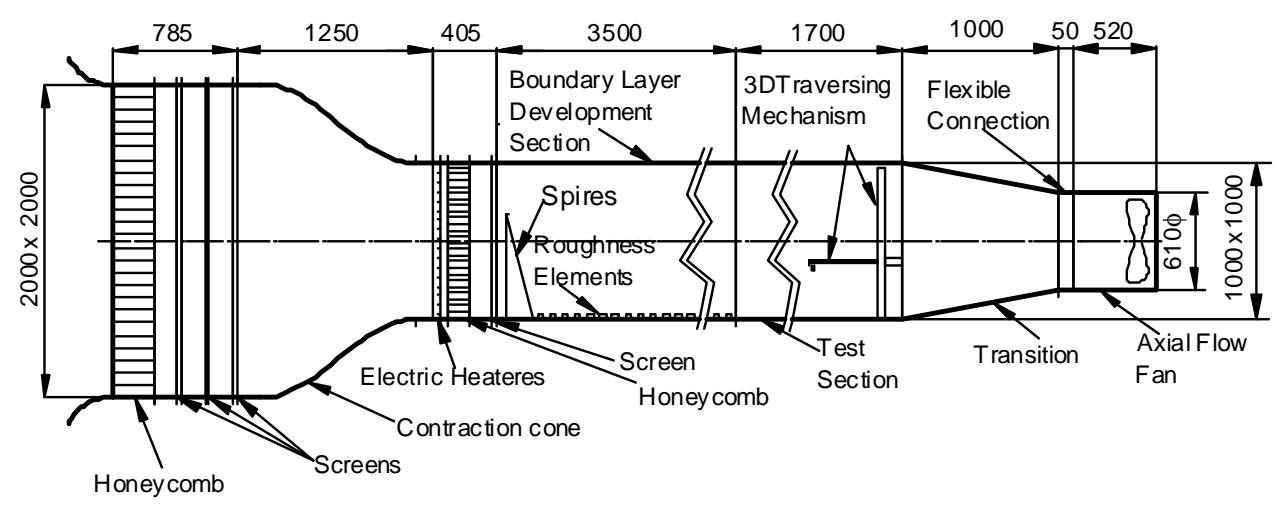

(b)

Figure 1: Design features of the present atmospheric boundary layer wind tunnel (ABLWT): (a) main flow sections coupled with the test section, (b) construction components and details (all dimensions in $\mathrm{mm}$ ).

\subsection{Upstream Settling Section}

The objective of this section is to allow air to enter the wind tunnel smoothly and to provide a spatially uniform flow of air at the beginning of the flow development section. The settling section consists of one honeycomb and three successive screens having different mesh sizes. The details of their design are described as follow. 


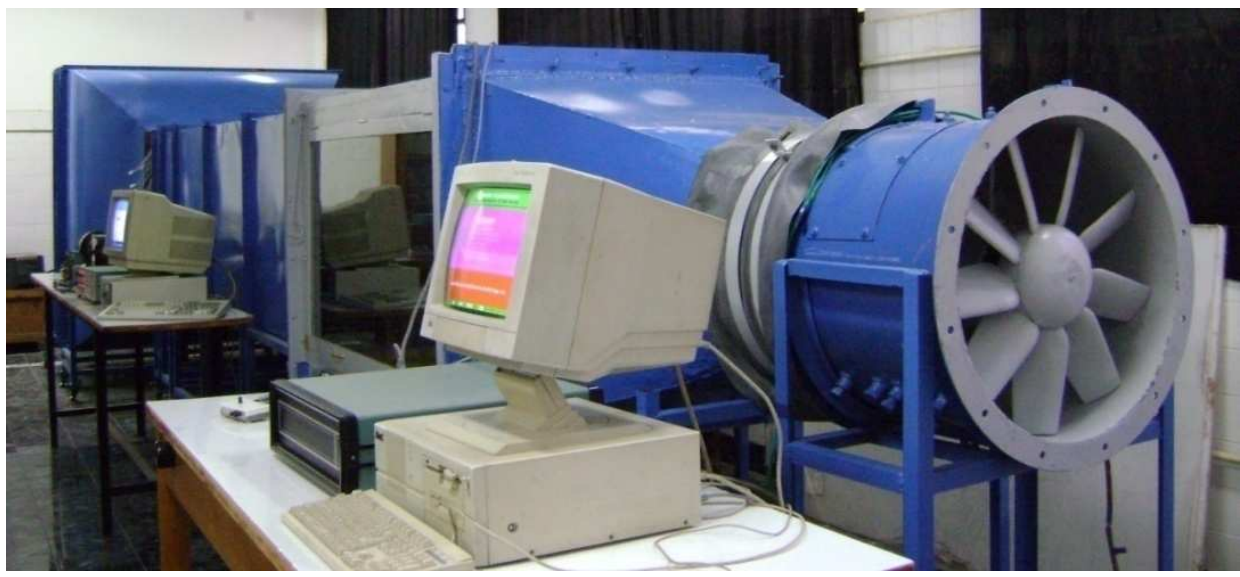

Figure 2: An overall photographic view of the present ABLWT with measuring and control facilities

\section{The honeycomb}

The honeycomb normalizes the flow into one direction (straightens the flow), breaks up eddies larger than the cell size, and reduce the free-stream turbulence level. The honeycomb is composed of circular shape cells having length-to-diameter ratio of 10 . This ratio is sufficient to straighten the flow as described in [13]. The designed honeycomb has been fabricated from PVC tubes having inner diameter of $23 \mathrm{~mm}$, wall thickness of $1 \mathrm{~mm}$, and length of $230 \mathrm{~mm}$. A total number of $6400 \mathrm{PVC}$ tubes were used to construct the honeycomb with cross section of $2 \mathrm{~m} \times 2 \mathrm{~m}$.

\section{The screens}

Screens are commonly used to improve flow quality in wind-tunnels because they are very effective in breaking up larger eddies and act primarily to reduce mean nonuniformity and fluctuations of the streamwise and cross-flow component. Seamless stainless-steel wire screens are placed in the settling duct for the reduction of turbulence levels of the incoming flow (out of the honeycomb). According to Mathew et al. [13], three screens are selected with open area ratios of 54\%, 45\%, and 54\%, with mesh per inch counts of 12,20 , and, 24, respectively. The screens are spaced at an axial distance of $150 \mathrm{~mm}$. This distance has been chosen for the wire generated turbulence to decay sufficiently $[3,14]$.

\subsection{Contraction Cone}

The contraction cone accelerates and aligns the flow with good quality as it enters into flow development section. The design parameters of contraction cone (size and shape) are determined in such a manner to minimize the turbulence intensity, obtain uniform and steady flow, and avoid flow separation $[12,13]$. The designed contraction has a total length of $1.25 \mathrm{~m}$, an area contraction ratio $\mathrm{CR}=4$, an aspect ratio at the entrance (width / height) $A R=1$, half inlet height $H_{i}=1 \mathrm{~m}$, and half outlet height $H_{o}=0.5 \mathrm{~m}$. The curved part of the contraction wall has a length $L=1 \mathrm{~m}$. The shape of this curved part has been formed according to a fifth-order polynomial given in [15] as: 


$$
\frac{y^{\prime}}{H_{i}}=f(\eta)=1-\left(1-\frac{H_{0}}{H_{i}}\right)\left(10 \eta^{3}-15 \eta^{4}+6 \eta^{5}\right)
$$

where $\eta=x^{\prime} / L, x^{\prime}$ and $y^{\prime}$ are the axial and vertical coordinates from the beginning of the contraction cone. Figure 3 shows the characteristics of the contraction cone wall. The plot of polynomial function $f(\eta)$ which corresponds to the curved wall shape at the half mid-plane is shown in Fig. 3-a. The design of contraction with this wall shape is evaluated by performing a numerical simulation inside the contraction cone using CFD software with standard $k-\varepsilon$ turbulence model. A plot of the axial wind velocity variation at the half mid-plane is shown in Fig. 3-b. The obtained results of the velocity contours show no separation inside the contraction cone. The curved part of the contraction cone is constructed by welding of four similar curved walls. Figure 4 shows the assembly of the contraction cone parts. The walls are fabricated by cold rolling of $1.5 \mathrm{~mm}$ thick galvanized iron sheets.

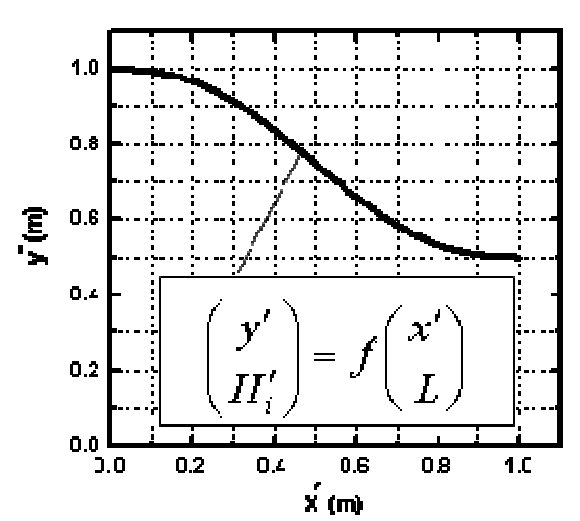

(a)

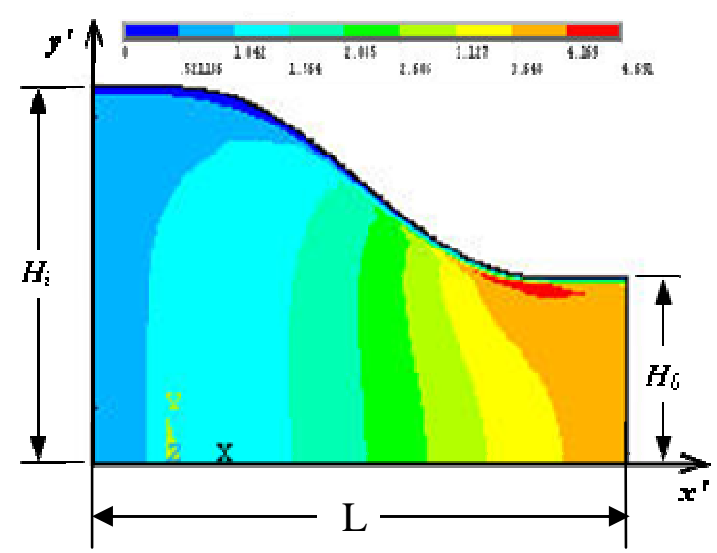

(b)

Figure 3: Contraction cone wall: (a) schematic of the polynomial forming the shape of the curved part of the contraction (b) contours of axial wind velocity along the half midplane for the contraction.

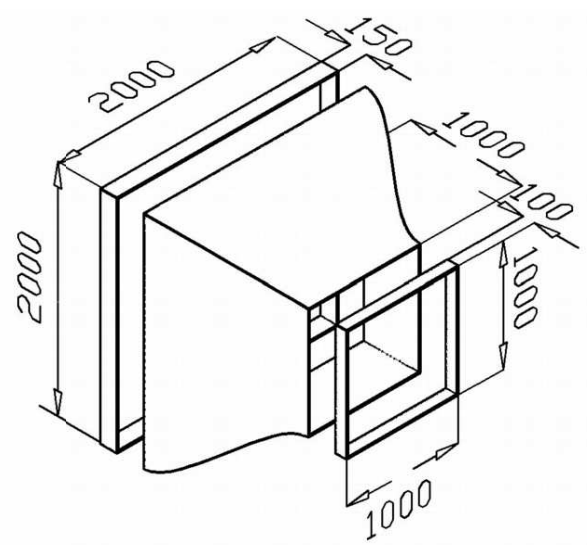

Figure 4: Assembly of the contraction cone parts (dimensions in $\mathrm{mm}$ ). 


\subsection{Air-Flow Heating Unit}

This unit is designed and fabricated to produce a thermally stratified atmospheric boundary layer. The unit consists mainly of twenty four electric heater rods, each of $8.5 \mathrm{~mm}$ diameter, $1 \mathrm{~m}$ length, and a maximum power of $1 \mathrm{~kW}$. In addition, two electric heater stripes (each $50 \mathrm{~mm}$ width, $1 \mathrm{~m}$ length, and maximum power of $1 \mathrm{~kW}$ ) are attached to the floor and ceiling of the unit. The heater rods are allocated vertically with $40 \mathrm{~mm}$ pitch. The electrical circuit of the heaters is arranged and provided with a control unit to supply specific electric power distribution among the heaters which leads to the desired temperature profiles within the simulated atmospheric boundary layer.

\subsection{After Heaters Settling Section}

The objective of this section is to counter balance the influence of the flow disturbance caused by the heating unit. It consists of one honeycomb and one screen. The honeycomb is designed with circular shape cells having $11 \mathrm{~mm}$ in diameter and $110 \mathrm{~mm}$ length. The screen is selected with open area ratio of $54 \%$, and mesh per inch counts of 12. Both the honeycomb and the screen are designed and fabricated in a manner similar to that considered in the settling section. The screen is located $150 \mathrm{~mm}$ downstream the honeycomb.

\subsection{Boundary Layer Development Section}

In this section, atmospheric boundary layer (ABL) of different thickness for different earth surface conditions is simulated. The boundary layer thickness, $\delta$ known to vary from place to place depending on the earth's surface characteristics (surface roughness). It might be as low as $200 \mathrm{~m}$ for smooth earth surface compared with higher values up to $600 \mathrm{~m}$ for surfaces with significant roughness. Typical values of $\delta$ are: 200 - $300 \mathrm{~m}$ for open sea and desertal areas, $300-400 \mathrm{~m}$ for rural areas, $400-500 \mathrm{~m}$ for wooden forests, and $500-600 \mathrm{~m}$ for urban areas $[4,16]$. A combination of spires and roughness elements on the floor of the wind tunnel are used to artificially simulate the earth surface condition correspond to the ABL under consideration. Figure 5 shows the important features and parameters considered in the design of the boundary layer development section. Section dimensions of height $H=1 \mathrm{~m}$, width $W=1 \mathrm{~m}$, and a total length of $3.5 \mathrm{~m}$, were found enough to develop a simulated boundary layer of thickness $\delta$ up to a value of $\delta^{*}=0.6 \mathrm{~m}$ (for urban area) which corresponds to an actual ABL thickness of $600 \mathrm{~m}$ (scale 1/1000). The design value of simulated ABL thickness is selected to be about half of boundary layer development section height $(\delta=H / 2)$. The remainder vertical distance is enough to eliminate the effects of the upper boundary layer of the wind tunnel. A good simulation of $\mathrm{ABL}$ wind motion has to take into account the categorization of $\mathrm{ABL}$ into main flow and boundary layer flow. Moreover, the main potential flow $\left(u=u_{\delta}\right)$ occurring above the ABL together with the boundary layer flow gives a complete simulation of the real ABL. The boundary layer flow can be characterized by the power law relation, given by

$$
\frac{u}{u_{\delta}}=\left(\frac{z}{\delta}\right)^{\alpha}
$$


where $z$, is the distance normal to the surface, $u$ is the corresponding mean velocity, and $u_{\delta}$ is the mean velocity at $z=\delta,[17,18]$. The exponent $\alpha$ depends, for an aerodynamically smooth surface, on the Reynolds number and, for a rough surface, on the roughness length. It interrelates with the boundary layer thickness $\delta$ and varies from values as low as $\alpha=0.12$ for smooth earth surfaces (e.g. open sea), to values as high as $\alpha=0.4$ (urban area) [4, 16]. A combination of triangular spires with splitter plates and cube roughness elements (Fig. 6) are selected and designed according to Irwin's method [19] described by the following equations.

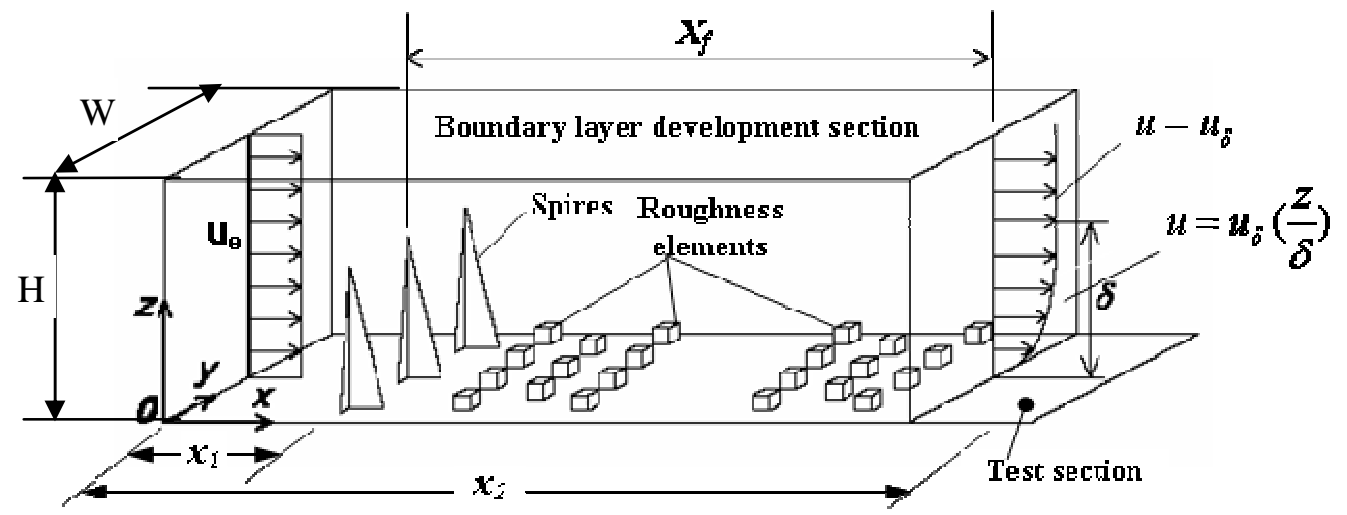

Figure 5: Conceptual model for the boundary layer development section illustrating the coordinates system, velocity distributions at the entrance and outlet, spires arrangement, and arrays of roughness elements.

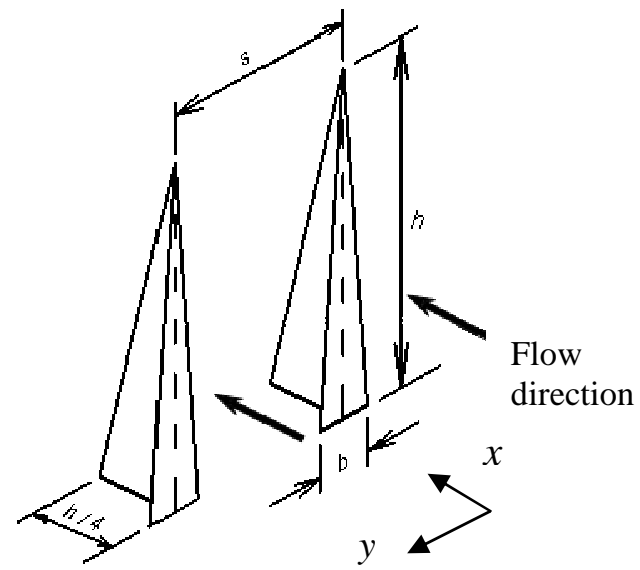

(a)

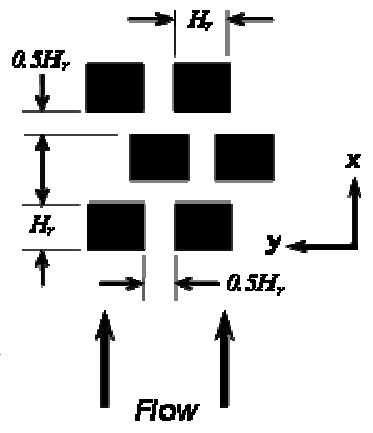

(b)

Figure 6: Schematic of configuration and dimensions of: (a) triangular spires with splitter plates (b) cube roughness elements.

\section{Spires arrangement}

Referring to Fig. 6-a, the total area of $N$ triangular spires with base length $b$, and height, $h$ is:

$$
A_{s}=N \frac{b h}{2}=\frac{\psi H W}{(1+\psi \theta) C_{D 0}},
$$


where

$$
\begin{aligned}
& \psi=\beta\left(\frac{2}{1+2 \alpha}+\beta-C_{f} \frac{x_{f}}{\delta} \frac{1+\alpha}{\alpha}\right) /(1-\beta)^{2} \\
& \beta=\frac{\delta}{H} \frac{\alpha}{1+\alpha}
\end{aligned}
$$

where $x_{f}$ is the distance downstream of the spires up to the end of the boundary layer development section, the local skin friction coefficient, $C_{f}$ in Eq. (4) is given by

$$
C_{f}=0.136\left(\frac{\alpha}{1+\alpha}\right)^{2}
$$

The true drag coefficient, $C_{D O}$, and the blockage factor, $\theta$, typically have values of 1.45 and 1.7 , respectively. These values correspond to the condition when $N$ spires are spaced within the section width $\mathrm{W}$, exactly with a pitch $s=h / 2$, (i.e. $N$ $=2 W / h)[19,20]$.

Substituting for $C_{D 0}, \theta$, and $N$, Eq. (3) becomes

$$
\frac{b}{h}=\frac{H}{h} \frac{\psi}{(1+1.7 \psi) \times 1.45}
$$

Considering the design dimensions of $H=1 \mathrm{~m}, W=1 \mathrm{~m}$, and $x_{f}=3.4 \mathrm{~m}$, together with urban conditions of $\alpha=0.28, \delta=0.6 \mathrm{~m}$, and the condition of $0.05<$ $b / h<0.2$, for effective spires as mentioned in [19], Eqs. (4) - (7) were solved to give optimum design data for the spires as $N=3, b=111 \mathrm{~mm}$, and $h=666 \mathrm{~mm}$ used in the present ABLWT.

\section{Arrays of roughness elements}

Arrays of roughness elements have been designed fabricated and distributed in a way to be a good simulation of real urban and industrial sites. Such sites can be simply modeled as plan area occupied by uniformly distributed regular obstacles having the shape of cube placed in staggered manner as shown in Fig. 6-b. The cubes (roughness elements) are designed to simulate large and compact (many close obstacles) urban, with frontal area density $\lambda_{f}=0.4-0.5$ [21]. For the cube arrays with cube height $H_{r}$, a selected value, $\lambda_{f}=4 / g \approx 0.44$ gives centerline spacing of $1.5 H_{r}$. A design value of $H_{r}=45 \mathrm{~mm}$ is obtained from the following relation [19]:

$$
\frac{H_{r}}{\delta}=\exp \left[\frac{2}{3} \ln \left(\frac{1.5 H}{\delta}\right)-0.1161\left(\frac{2}{C_{f}}+2.05\right)^{0.5}\right] \text {, }
$$

Three spires and 710 cubes, fabricated from wooden bares and plates are mounted at the spacing and pattern described above on wooden plates covering the plan area of the boundary layer development section of $3.4 \mathrm{~m}^{2}$ (see Fig. 7).

\subsection{Test Section}

The test section (Fig. 8) is the chamber in which fabricated test models are mounted to simulate different urban areas common objects exposed to wind flow with varying direction. The test section is provided with the main instrumentation to measure the 
various flow characteristics (velocity, temperature, pollutant dispersion...etc.). The side walls of the test section are made of glass panels (see Fig. 8-a) to allow visualization of various flow phenomena occurring in the atmosphere surrounding the test model. The effective dimensions of the test section are $1 \mathrm{~m}$ height, $1 \mathrm{~m}$ width and $1.7 \mathrm{~m}$ length. The main components of the test section are the turntable and the traversing mechanism (see Fig. 8-b).

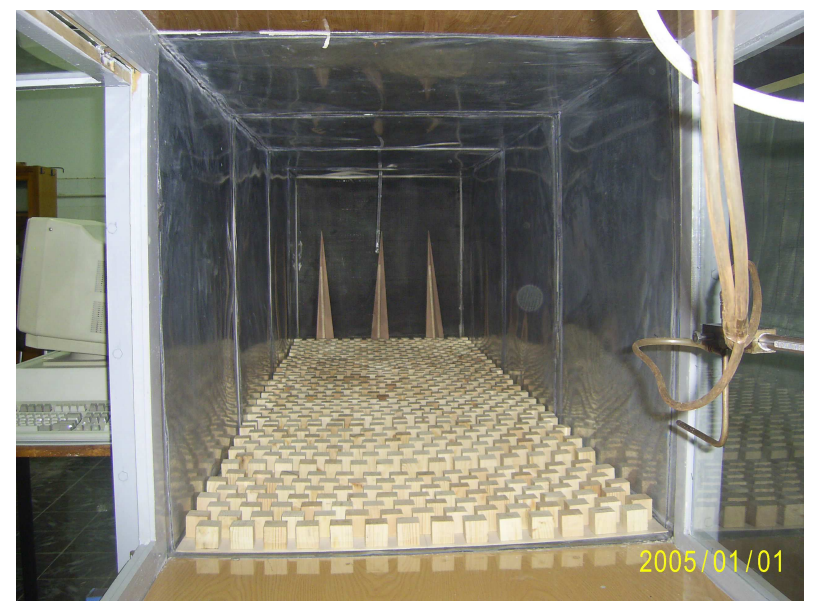

Figure 7: A Photographic view of spires arrangement and arrays of roughness elements inside the boundary layer development section.

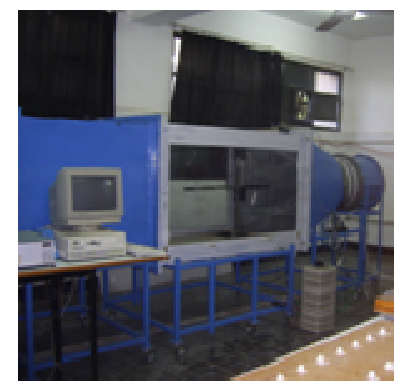

(a)

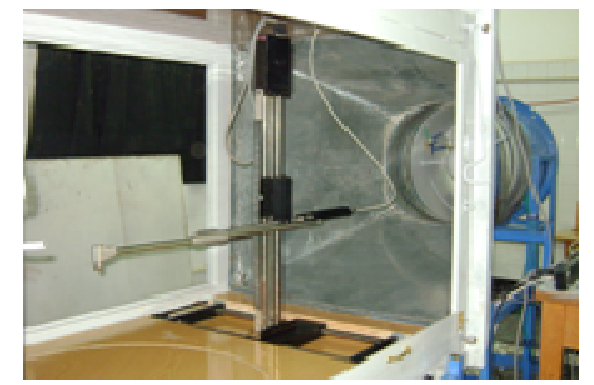

(b)

Figure 8: Detailed photographic views of: (a) test section from outside, (c) test section from inside showing the turntable and traversing mechanism.

\section{Turntable}

The turntable baseplate is designed to have a circular flat surface area $(0.80 \mathrm{~m}$ in diameter) on which different test models are mounted. The baseplate is centered on the floor of the test section at the mid distance between the side walls and at $0.6 \mathrm{~m}$ from the test section entrance. The baseplate is equipped with a rotation mechanism from beneath, to produce the variation of wind flow direction with respect to the test model configuration. The rotation mechanism is designed to have a mobility of $\pm 360^{\circ}$ with direction variation increments of $2.5^{\circ}$. 


\section{Traversing mechanism}

The environmental flow studies are usually performed through the measurements of flow characteristics at hundreds of points covering the space of the simulated atmospheric boundary layer surrounding the test model. Accordingly, a device is needed to enable performing such measurements in all directions economically and without interrupting the flow field. A three-dimensional (3D) traversing mechanism, to which probes or sensors are attached, is an appropriate device for this task. A 3D computer-linked traversing mechanism model 57H10/11 manufactured by Dantec Corporation, Denmark has been selected and installed at the end of the test section. The mechanism is driven by three DC motors for the traversing in the three directions. The mechanism can cover traversing distances of $0-800 \mathrm{~mm}$ in the axial direction, $0-900$ $\mathrm{mm}$ in the lateral direction, and $0-900 \mathrm{~mm}$ in the vertical direction at an increment of $0.000 \mathrm{~mm}$ in all directions.

\subsection{Transition and Flexible Connection}

A square $(1 \mathrm{~m} \times 1 \mathrm{~m})$-to-round transition fitting has been designed and constructed to join the test section to the $0.61 \mathrm{~m}$ diameter entrance of the fan, via a flexible connection. The transition fitting is a slowly converging section with $1 \mathrm{~m}$ length and an area ratio of 3.40. The objective of the flexible connection is to isolate the mechanical vibrations associated with the fan rotation from the main body of the wind tunnel. Therefore, the flexible connection is made from rubber $1 \mathrm{~mm}$ thick, with adjustable length from $50-100 \mathrm{~mm}$. Referring to the above discussion and description of the test section, the distance between the turntable and the entrance of the transition section in addition to its length are believed to be enough to eliminate the effects of any variations that might occur downstream the transition section on the flow above the turntable.

\subsection{Axial Flow Fan}

A $2 \mathrm{~kW}$, axial-flow fan with maximum flow rate of $4 \mathrm{~m}^{3} / \mathrm{s}$ at $1440 \mathrm{rpm}$ is selected to drive the wind tunnel. The fan is operated by a variable speed motor to give adjustable rpm settings via the use of a three phase variable voltage automatic transformer.

\section{WIND TUNNEL CHARACTERIZATION}

A preliminary characterization of the above designed and constructed wind tunnel facility has been performed using available measuring devices and instrumentation. The aim of the preliminary characterization is to insure the existence of the basic flow characteristics inherent to the simulation of the atmospheric boundary layer in the present wind tunnel. These flow characteristics can be described by the uniformity of the flow at the entrance of the boundary layer development section, and the boundary layer flow velocity profile with the required parameters $(\delta$ and $\alpha)$ associated with the designed spires and roughness elements arrays. The measurements of the mean axial velocity profiles in the mid vertical plane were performed for cold wind flow under different operating conditions. These measurements were carried out using a Pitotstatic tube in conjunction with inclined differential manometer having a sensitivity of 
$0.4 \mathrm{~Pa}$, and a full scale deflection corresponding to $800 \mathrm{~Pa}$. The flow velocity is calculated using the manometer reading by the well-known Bernoulli equation for steady one-dimensional flow of an incompressible fluid. The accuracy of the resulting velocity values has been estimated to be within $\pm 10 \%$ relative error. The velocity profile at the entrance of the boundary layer development section is measured with the Pitot-static tube attached to simple manual traversing mechanism especially designed and manufactured for the present study. The vertical mean velocity profiles were measured at 70 different heights. The following discussion deals with the obtained experimental results for three groups of experiments. These are, experiments in the empty wind tunnel, experiments in the wind tunnel with spires only, and experiments in the wind tunnel with the combination of spires and arrays of roughness elements.

\subsection{Experiments in the Empty Wind Tunnel}

Figure 9 shows the measured mean velocity profiles for different fan speeds at the entrance of the boundary layer development section and the test section (at $x_{1}$ and $x_{2}$ shown in Fig. 5). The velocity profiles are almost identical to each other for a fan speed of $500 \mathrm{rpm}$ which mean that the velocity is stable. The velocity profiles at the entrance of the boundary layer development section $\left(x_{l}=15 \mathrm{~cm}\right)$ show good uniformity across the whole height for all fan speeds, except for the boundary layer effect within $5 \mathrm{~cm}$ above the lower smooth surface. Similar uniform velocity profile is obtained at the entrance of the test section $\left(x_{2}=360 \mathrm{~cm}\right)$ which can be noticed only for $500 \mathrm{rpm}$. This value of fan speed gives a Reynolds number of $2.9 \times 10^{5}$ (laminar flow). The increase in the boundary effect for the other fan speeds $(1000,1440 \mathrm{rpm})$ is due to the turbulent flow associated with higher values of Reynolds, $R e>5 \times 10^{5}$.

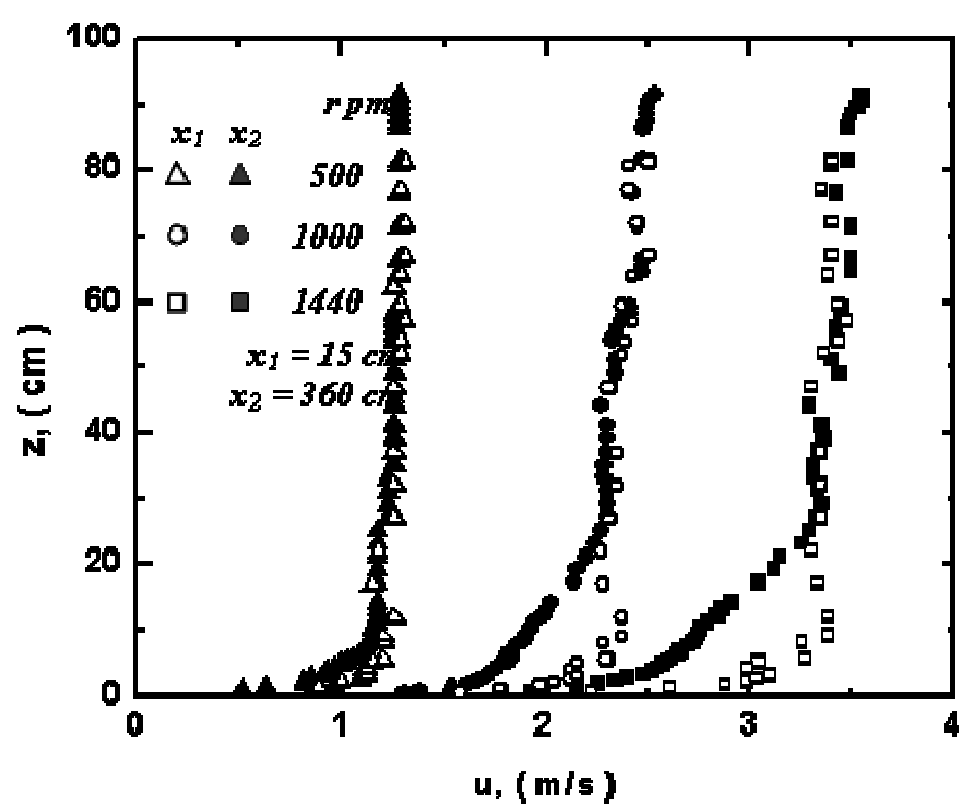

Figure 9: Mean velocity profiles at different fan speeds in the empty wind tunnel. 


\subsection{Experiments with Spires Only}

The reason for adding the spires is to generate a thick boundary layer in a short distance. This can be clearly shown by comparing the measured mean velocity profiles with and without spires (Figs. 9 and 10) at the entrance of the test section $\left(x_{2}=360\right.$ $\mathrm{cm})$. After installing spires, it is seen that the velocity profiles for the three fan speeds became similar to each other, and the boundary layer thickness grew from about $20 \mathrm{~cm}$ to $35 \mathrm{~cm}$. The similarity of the three velocity profiles means that the flow regime is independent of the Reynolds number, so the flow with spires is a fully developed turbulent flow. Using the power law to fit the measured data of Fig. 10 and considering a boundary layer thickness $\delta=35 \mathrm{~cm}$, an exponent of the power law $\alpha=0.12$ was obtained. These values of $\delta$ and $\alpha$ are for the measured velocity profiles shown in Fig. 10 which resulted from a combination effects of spires and a smooth surface. This combination simulates a real case of smooth earth surface with $\delta$ about $300 \mathrm{~m}$ and $\alpha=$ 0.12 (e.g. open sea).

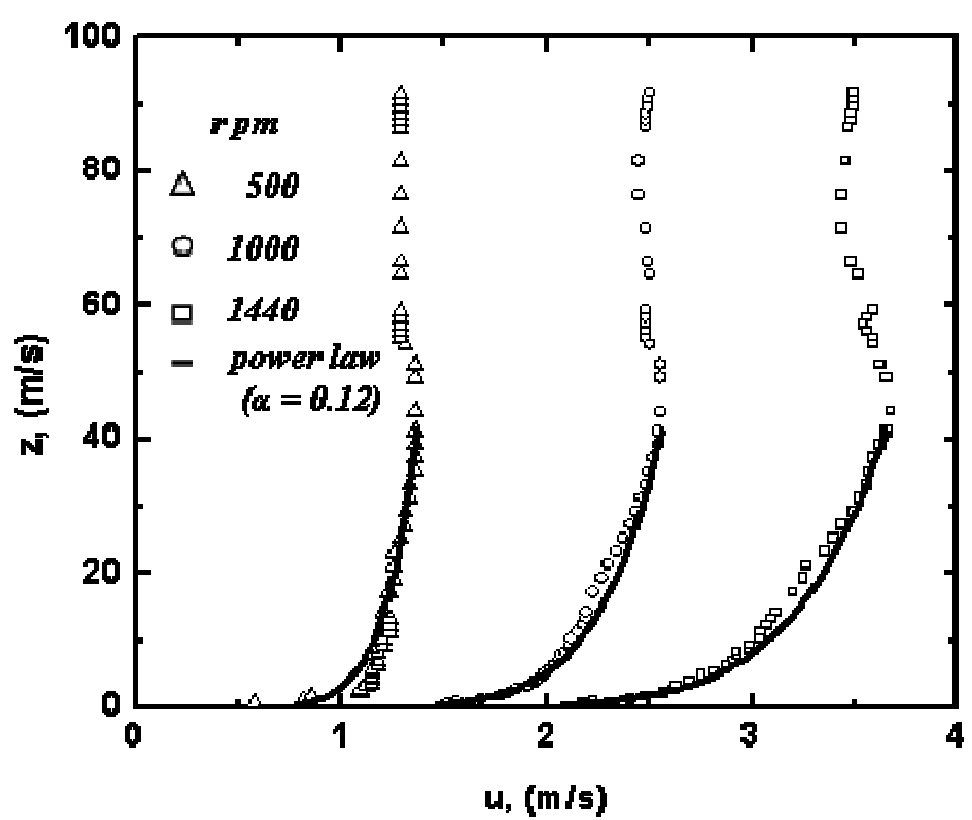

Figure 10: Mean velocity profiles in the wind tunnel at different fan speeds, with spires only.

\subsection{Experiments with Spires and Roughness Elements}

Figure 11 shows the measured mean velocity profiles for different fan speeds at the entrance of the test section with the combination of designed spires and arrays of roughness elements installed in the wind tunnel. As it is expected, the profiles indicate a simulated boundary layer thickness of about $60 \mathrm{~cm}$ (the design value of $\delta$ ). Using the power law to fit the measured data of Fig. 11 with $\delta=60 \mathrm{~cm}$, an estimated value of the exponent $\alpha$ of 0.25 was obtained. The estimated value, even it corresponds to urban area condition, it is somewhat less than the value of $\alpha=0.28$ used in the design of spires and roughness elements as mentioned above. This is due to the deviation 
between real and theoretical design conditions describing the shape dimensions and orientation of the spires and roughness elements.

All groups of experiments show little scattering of the points (see Figs. 9-11) representing the results for the mean velocity. This is mainly explained by the combined effect of measuring and allocation errors. However, for all measured mean velocity profiles, one can clearly notice the features of the main flow and boundary layer characteristics. The repetition of the main features for the mean velocity profiles, for different conditions, indicates the good reproducibility of the present wind tunnel.

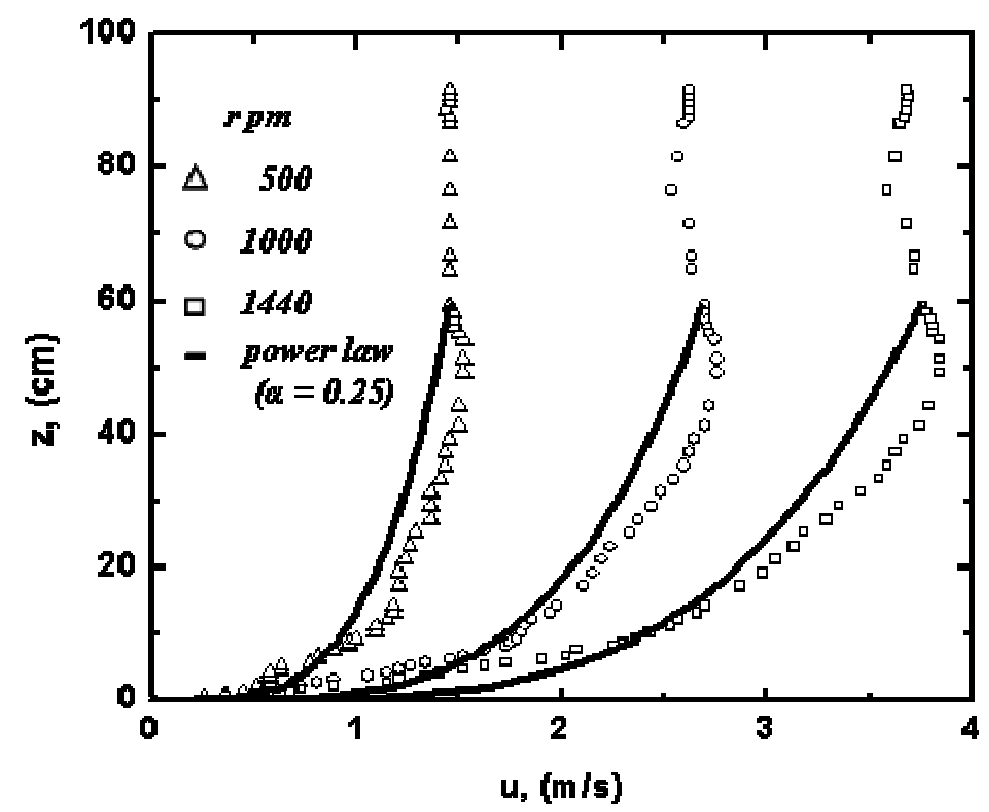

Figure 11: Mean velocity profiles in the wind tunnel at different fan speeds, with spires and arrays of roughness elements.

\section{CONCLUSIONS}

The design, construction, and preliminary characterization of the atmospheric boundary layer wind tunnel facility for environmental flow studies at Assiut University are presented. The constructed low speed-open loop wind tunnel is driven by a $2 \mathrm{~kW}$, $4 \mathrm{~m}^{3} / \mathrm{s}$, axial flow fan. The fan is controlled by a variable speed motor. The wind tunnel consists of flow straightening section, long flow development section, test section, and flow support section. Spires arrangement and arrays of roughness elements are designed, fabricated, and mounted in the flow development section to artificially simulate the atmospheric boundary layer for urban areas. Preliminary facility characterization experiments were performed. From the results of the mean velocity profiles with different conditions, the following remarks can be concluded.

1. The velocity profiles produced at the entrance of the test section are quite stable insuring a steady flow conditions.

2. The velocity profiles introduced by the flow straightening section are almost uniform. This condition is needed for the design of the artificial elements or 
objects (spires and roughness elements) used to develop the simulated atmospheric boundary layer.

3. The use of spires is effective in generating a thick boundary layer in a short distance.

4. The power law with the appropriate parameters proved to be suitable in fitting the velocity profiles within the simulated atmospheric boundary layer.

5. The present wind tunnel possesses a good reproducibility, a condition that gives confidence in the results obtained from its use for long run investigations.

6. The experimentally simulated atmospheric boundary layer was shown to be fully developed with the use of spires and roughness elements. This is consistent with the Irwin's method followed in the design of these elements.

\section{REFERENCES}

[1] Yassin, M. F., "Study on Pollutant Dispersion within Urban Area under Changes of Atmospheric Stability and Wind Direction", Ph. D. Thesis, Graduate School of Faculty of Engineering, University of Tokyo, Japan, Environmental Engineering, 2004.

[2] Cermak,J. E., "Wind-Tunnel Development and Trends in Applications to Civil Engineering", J. of Wind Engineering and Industrial Aerodynamics Vol. 91, No. 3, 2003, pp. 355-370.

[3] Lindgren, B., and Johansson, A., "Design and Evaluation of a Low-Speed WindTunnel With Expanding Corners" Royal Institute of Technology, Department of Mechanics, Sweden, Technical Report TRITA-MEK 2002:14, 2002.

[4] Krishna, M. K, Mahalingegowda, R. M, "Atmospheric Boundary Layer Wind Tunnel Design", Turbulence Energy \& Combustion Group (TEC), The University of Adelaide, Adelaide SA 5005, Australia. pp. 169-174.

[5] Balendra, T., Shah, D. A., Tey, K. L., and Kong, S. K., "Evaluation of Flow Characteristics in the NUS-HDB Wind Tunnel", J. of Wind Engineering and Industrial Aerodynamics, Vol. 90, No. 6, 2002, pp. 675-688.

[6] Meroney, R. N., Pavageau, M., Rafailidis, S., and Schatzmann, M., "Study of Line Source Characteristics for 2-D Physical Modeling of Pollutant Dispersion in Street Canyons", J. Wind Engineering and Industrial Aerodynamics, Vol. 62, No. 1, 1996, pp. 37-56.

[7] De Bortoli, M. E., Natalini, B., Paluch, M. J., and Natalini, M. B., "Part-Depth Wind Tunnel Simulations of the Atmospheric Boundary Layer", J. Wind Engineering and Industrial Aerodynamics, Vol. 90, No. 4-5, 2002 , pp. 281-291.

[8] Snyder W., H., "Wind-Tunnel Study of Entrainment in Two Dimensional DenseGas Plumes at the EPA's Fluid Modeling Facility", J. Atmospheric Environment, Vol. 35, No. 13, 2001, pp. 2285-2304.

[9] Burton, W. V., "Wind Tunnel Simulation of an Atmospheric Boundary Layer ", M. Sc. Thesis, Graduate Faculty of Texas, Tech University, Mechanical Engineering, 2001. 
[10] Mare, C., "Effects of Stratification on Flow and Dispersion around Obstacles in Turbulent Boundary Layers", Ph. D. Thesis, School of Engineering, University of Surrey, UK, 2003.

[11] Ohya, Y., Tatsuno, M., Nakamura, Y., and Ueda, H., "A Thermally Stratified Wind Tunnel for Environmental Flow Studies", J. Atmospheric Environment, Vol. 30, No. 16, 1996, pp. 2881-2887.

[12] Mehta, R. D., and Bradshaw, P., "Design Rules for Small Low Speed Wind Tunnels", J. Aeronautical, Paper No. 718, 1979, pp. 443-449.

[13] Mathew, J., Bahr, C., Carroll, B., Sheplak, M., and Cattafesta, L., "Design, Fabrication, and Characterization of an Anechoic Wind Tunnel Facility", 11th AIAA/CEAS Aeroacoustics Conference (26th AIAA Aeroacoustics Conference) 23 - 25 May 2005, Monterey, California.

[14] Buxton, T., Fleet, T., Israel, D., Heilman, J., Humphrey, J., Mongiardo, J.,"The Wandering Wind Tunnel", Barberton High School 489 Hopocan Avenue Barberton, 1995, research project.

http://www.grc.nasa.gov/WWW/K12/WindTunnel/wandering_windtunnel.htm

[15] Doolan, C. J., " Numerical Evaluation of Contemporary Low-Speed Wind Tunnel Contraction Designs", J. Fluids Engineering, Vol. 129, No. 9, 2007, pp. 1241-1244.

[16] Barbosa, P. H. A., Cataldi, M., Freire, and A. P. S., "Wind Tunnel Simulation of Atmospheric Boundary Layer Flows", J. the Brazilian Society of Mechanical Sciences, Vol. 24, No. 3, Rio de Janeiro July 2002, pp. 177-185.

[17] Pavageau, M., and Schatzmann M., "Wind Tunnel Measurements of Concentration Fluctuations in an Urban Street Canyon", J. Atmospheric Environment, Vol. 33, No. 24-25, 1999, pp. 3961-3971.

[18] Wittwer A. R., and Moller, S.V., "Characteristics of the Low-Speed Wind Tunnel of the UNNE", J. Wind Engineering and Industrial Aerodynamics, Vol. 84, No. 3, 2000, pp. 307-320.

[19] Irwin, H. P. A. H., "The Design of Spires for Wind Simulation", J. of Wind Engineering and Industrial Aerodynamics, Vol. 7, No. 3, 1981, pp. 361-366.

[20] Wang, M., "Application of Laser Doppler Velocimetry to Measurement of the Velocity Field Close to Regularly Arrayed Rough Surfaces", Ph. D. Thesis, Chemical Engineering, University of Arkansas, USA, 2006.

[21] Hanna S. R., and Britter R., "The Effect of Roughness Obstacles on Flow and Dispersion in Urban and Industrial Areas", 7th Int. Conf. on Harmonisation within Atmospheric Dispersion Modeling for Regulatory Purposes, Belgirate, Italy, May 28-31, 2001, pp. 266-270. 


\section{تصميم وإنشاء نفق الرياح لاراسات التدفق البيئية}

م. حمود النهاري ، د. على كامل عبد الرحمن ، د. عبد المنعم نصيب و أ.د. حمدي معوض شافعي

تعرض هذه الدر اسة تفاصيل التصميم والإنشاء والتشخيص المبدئي لنفق الرياح المحاكي لطبقات الجو

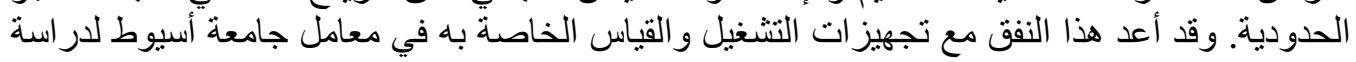

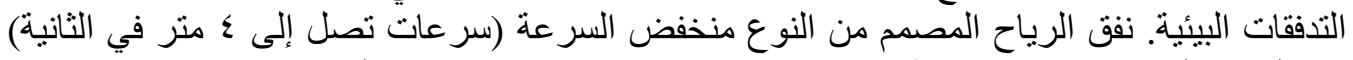

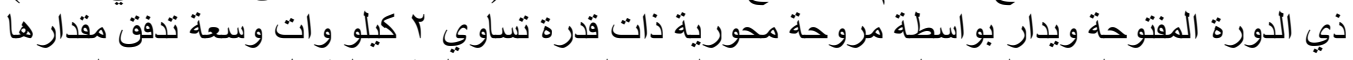

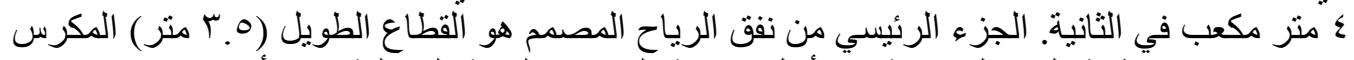

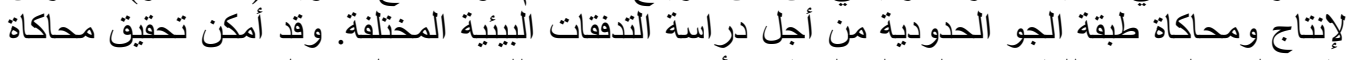

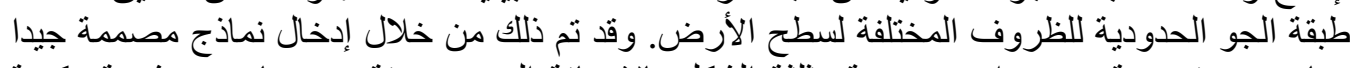

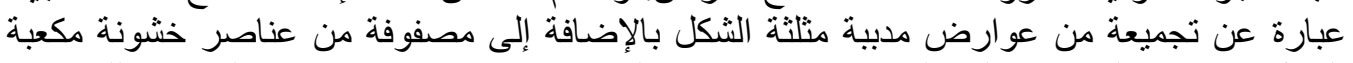

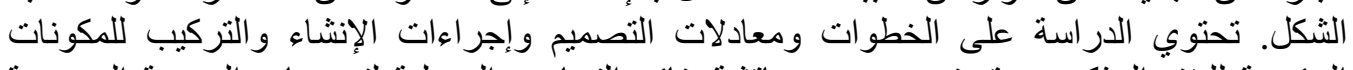

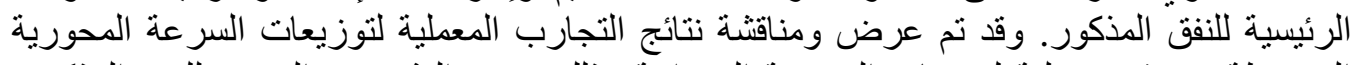

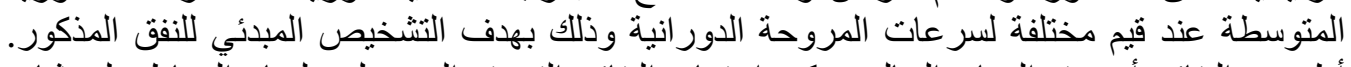

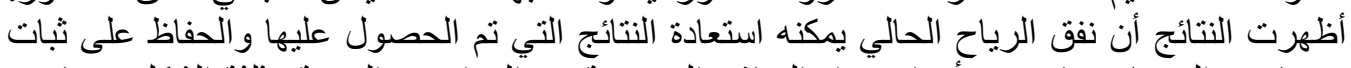

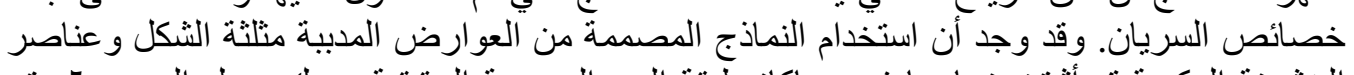

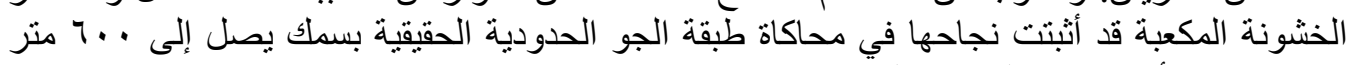
(فوق سطح الأرض) في المناطق الحضرية. 